\title{
Waiting lists not pharmacare main issue: feds
}

The federal government, Roy Romanow and Dr. David Naylor all purport that waiting lists - not pharmacare — should dominate the agenda at this week's (Sept. 13-16) First Ministers' conference on health care.

Federal Health Minister Ujjal Dosanjh says governments must provide catastrophic drug coverage so Canadians don't face financial ruin over the costs of their prescribed drugs, but he maintains that reducing waiting times are the meeting's main deliverable. "A lack of timely access is eroding the system," says Dosanjh. The Liberals campaigned in June's election to significantly reduce waiting times over 5 years in 5 key areas: cancer treatment, cardiac care, diagnostic imaging, joint replacement and sight restoration.

The proposed national pharmacare program is sketchy on details, but would basically see the federal government pay all the costs for drugs now covered in the provincial and territorial formularies. This could run to between $\$ 7.5$ to $\$ 12$ billion annually. The premiers maintain that this would free up provincial funds to devote to reducing waiting lists.

A national pharmacare plan should be established "eventually," says Romanow, the former head of the Royal Commission into the Future of Health Care in Canada, but it "must be integrated into a series of reforms that have been neglected for too long...." It must also operate under the auspices of an independent body that links costs with health outcomes "so Canadians can make an informed decision."

Naylor, dean of medicine at the University of Toronto, dismissed the pharmacare scheme as "the political theme of the moment," during a speech to CMA's General Council on Aug 16. Waiting times must first be addressed, he said. This involves setting benchmarks for acceptable waiting times, measuring waiting times for specific procedures and targetting initiatives to deal with bottlenecks. "There is a lot of misinformation," he said. More money and health care professionals are also needed, Naylor maintained. "The devil will be in the details ... in our fractious federation."

Dosanjh hopes to soothe that political beast by negotiating a formal dispute resolution procedure with the premiers that "would give the provinces a voice and enable an independent panel of experts to assess if the Act has been breached and, if so, to recommend appropriate action." Such a proposal will "keep the politics - and by that I mean the bickering — to a minimum, making it more transparent and impartial." Canadians "want their government to fight for medicare, not over medicare," he concluded.

Dosanjh's stated priorities for the meeting include defending the Canada Health Act, addressing waiting times, improving access to health professionals, ensuring coverage for catastrophic drug costs, providing accountability in the health system and ensuring the financial sustainability of the health care system. - Barbara Sibbald, CMAJ

\section{INFECTIOUS DiseAsE}

\section{Pregnant Aboriginals more likely to be HIV positive}

A public health advisor wants physicians to be aware of new research showing a relatively high rate of HIV infection among pregnant Aboriginal women. Patients in this group should be tested and if necessary treated to reduce the possibility of transmission of HIV to their babies, said David Martin.

Martin, a program medical officer with Health Canada in Vancouver, coordinated a 3-year study (September 2000 to 2003), during which blood samples were taken from 5242 pregnant Aboriginal women. A total of 15 tested positive for HIV; 7 times more than what would be expected in the general population.

"The objective was to find out what the prevalence of HIV was in that group. We focused on the prenatal population because . . . they're coming in on a regular basis for testing. They're a fairly representative group of First Nations people."

Because the study was conducted anonymously, none of the women who tested positive were notified, a fact that drew criticism from some Aboriginal groups. Kevin Barlow, head of the Canadian Aboriginal AIDS Network, said "Without any direct way of informing certain study participants that they have tested HIV positive, substantial ongoing efforts need to be taken to educate Aboriginal women about all the implications of these findings."
Martin notes the research was done with support from the BC First Nations Chiefs' Health Committee, and approved by the UBC ethics review board. The study was designed to allow participants to remain anonymous.

"If this was the only way for them to be HIV tested, this would certainly be unethical," said Martin. However, he noted women can be tested at any time through their physicians.

Martin said women in urban areas outside BC would be similarly at risk. "I would be concerned that rates might be high as well in other provinces as a result of . . . intravenous drug activity." - Deborah fones, Vancouver 